East African Medical Journal Vol. 85 No. 8 August 2008

NUTRITIONAL AND ORAL HEALTH STATUS OF AN ELDERLY POPULATION IN NAIROBI

E.M. Ngatia, BDS, MSc (Nutrition), Lecturer, Department of Paediatric Dentistry and Orthodontics, L.W. Gathece, BDS, MPH, Senior Lecturer, F.G. Macigo, BDS, MPH, Senior Lecturer, T.K. Mulli, BDS, Assistant Lecturer, L.N. Mutara, BDS, MPH, Lecturer, Department of Periodontology, Community and Preventive Dentistry and E.G. Wagaiyu, BDS, MSc (Periodont. Lond), Senior Lecturer, School of Dental Sciences, University of Nairobi, P.O. Box 19676-00202, Nairobi, Kenya

Request for reprints to: Dr. E.M. Ngatia, School of Dental Sciences, University of Nairobi, P.O. Box 19546-00202, Nairobi, Kenya

\title{
NUTRITIONAL AND ORAL HEALTH STATUS OF AN ELDERLY POPULATION IN NAIROBI
}

\author{
E.M. NGATIA, L.W. GATHECE, F.G. MACIGO, T.K. MULLI, L.N. MUTARA and E.G. WAGAIYU
}

\begin{abstract}
Objective: To determine the nutrition and oral health status of elderly persons in Nairobi, Kenya.

Design: A cross-sectional study.

Setting: Households in Dagoretti Division of Nairobi.

Subjects: Two hundred and eighty nine persons $(29.8 \%$ males and $70.2 \%$ females) aged 45 years and above were assessed.

Results: The level of malnutrition using the mid upper arm circumference was $18.8 \%$ while by body mass index was $11.4 \%$. Of the population assessed, $46.4 \%$ had normal nutritional status while $40.9 \%$ were overweight, with more females $(48.0 \%)$ than males $(25.9 \%)$ being overweight. The study established that many of the elderly persons suffered from dental problems, especially periodontitis with $89.9 \%$ having dental plaque, calculus $85.6 \%$, gingival recession $82.5 \%$ and bleeding gums $77.4 \%$. The decayed index missing and filled teeth, was 7.173 with $19.7 \%$ caries free, $51.9 \%$ reported tooth mobility and edentulousness was common.

Conclusions: Under-nutrition, obesity and dental problems are issues of concern among the elderly. There is need to develop policies that will look into the nutrition and dental health of the elderly in order to improve their welfare.
\end{abstract}

\section{INTRODUCTION}

According to UN demographic projections, the world population aged 60 years and above is increasing rapidly. It is estimated that by the year 2025, there will be about 1.2 billion people above the age of 60 years worldwide. The older population in Africa currently estimated to be slightly over 42 million is projected to reach 205 million by 2050 (1).

Most of the old people in developing countries enter old age after a life of poverty and deprivation, with poor access to healthcare, and inadequate diet in quality and quantity. Majority of these elderly people suffer from various problems ranging from extreme poverty, ill-health, poor nutrition, lack of adequate care, shelter, clothing, isolation, mental and physical abuse. Many of them also suffer from age related health problems such as hypertension, diabetes, cancer, tuberculosis, arthritis and ophthalmologic diseases especially poor eyesight (2).

In the recent years there has been a growing awareness in the dental profession that the dental needs of the elderly people have been generally neglected and that the problem requires attention. The oral tissues are a critical part of the human body system, and the oral cavity is the gateway to the rest of the body systems. Factors associated with old age such as reduced salivary flow rate, quality and quantity, lowered immunity and the reduced ability of the body to repair itself, may aggravate 
the process of the degradation of the oral tissues. Oral diseases and tooth loss cause difficulties in chewing. This may in turn lead to selection of soft diets, which in most cases are composed of refined carbohydrates. This would easily predispose them to malnutrition and general ill health. Other difficulties associated with poor oral health status include difficulties in speech, deformed facial profile and loss of self-esteem (4).

Nutrition has been expressed as a right in international human instruments since 1924, and has been confirmed through numerous declarations and conventions such the 1948 Universal Declaration of Human Rights, the 1966 International Covenant on Economic, Social and Cultural Rights, the 1979 Convention on Elimination of all forms of Discrimination Against Women, the 1989 Convention on the Rights of the Child and the 1992 Declaration on Nutrition. Good nutrition is the key to the healthy development of individuals, families and societies. There is growing reason to believe that improving the nutrition of the most vulnerable groups in the community, will contribute to some of the greatest health challenges facing the world, including the burden of chronic degenerative diseases, malaria and AIDS (5).

In 1981, a collaboration working group of WHO/ FDI formulated a number of oral health goals to be achieved as a measure of the attainment of "health for all by the year 2000". As declared in 1979, one of these goals covered the elderly and stated that, "by the year 2000, a 25\% reduction in the present (1981) level of edentulousness at the age greater than 65 years will be achieved. It was also recommended that, greater than $50 \%$ of persons in this age group should be able to retain a minimum of 20 functional teeth (6). However, this goal has not been attained yet. The purpose of this study was to determine the nutrition and oral health status of elderly persons in Dagoretti division of Nairobi province with a goal to provide data that may be useful for health policy development and programme planning.

\section{MATERIALS AND METHODS}

A cross-sectional study was carried out in Waithaka and Riruta locations of Dagoretti Division in Nairobi province, during the month of August 2003. The two locations were conveniently selected. All households with a person aged above 45 years was included in the study. These are the areas in which it was possible to find the people of the selected age groups at home, based on the fact that the survey could only be conducted during the day. The two locations have similar characteristics, urban low to middle class socio-economic status.

Using a prevalence of $82 \%$ periodontal diseases among the older participants (7), at a confidence interval of $95 \%$, a significance level of 0.05 and a power of $80 \%$, a sample of 260 was computed. Considering an attrition rate of $10 \%$, a minimum sample size of 286 was arrived at. Quantitative data was collected from 289 households using a semistructured questionnaire. The questionnaire was only administered to those households with persons aged 45 years and above who were present at the time of data collection.

In-depth interviews and focus group discussions were used to collect qualitative data. Information on selected demographic and socio-economic household characteristics, health and food security was documented. Two focus group discussions were conducted one in each location. The participants were drawn from community members, both male and female aged 45 years and above who were not included in the household survey. Each focus group discussion comprised male and female participants drawn from among the elderly in the community, a moderator and two notes takers. The focus group discussions were conducted in an atmosphere that allowed for freedom of expression amongst the participants.

In-depth interviews were conducted with selected key informants from the community as well as health facilities, using a structured interview guide. Oral health status was assessed by dental examination using a standard WHO assessment form (8).

The nutritional status was assessed using body mass index (BMI) and mid upper arm circumference (MUAC). The measurements taken for assessment of nutrition status included weight, height, arm span and mid upper arm circumference. However, the arm span was only taken for the elderly who could not stand straight.

The research assistants were year three and four dental students from the University of Nairobi Dental Hospital. They were trained on the data collection tool as well as dental health examination and nutrition assessment. A pilot study was carried out to pre-test the research instruments, and necessary modifications made prior to actual data collection. 


\section{RESULTS}

Demographic characteristics of the study population: A total of 289 respondents were interviewed, $63 \%$ from Waithaka location and 37\% from Riruta. Majority of the respondents were females $70.2 \%$, while males were $29.8 \%$. Of the respondents, $39.1 \%$ were aged between $45-54$ years, $26.0 \%$ aged 55-64 years and 65 years and above were $34.9 \%$. The mean age was 60.6 years with a standard deviation of 12.6 and a range of 45-115 years.

Of the respondents $42.9 \%$ had never been to school, $8.3 \%$ had completed primary education, $9.0 \%$ had joined secondary school but only $7.6 \%$ had completed secondary school. Only $2.1 \%$ had gone beyond secondary level of education.

In regard to marital status, $48.1 \%$ of them were married, of whom 135 were in a monogamous marriage and four were polygamous. About 33.2\% were widowed, $12.8 \%$ single and $5.5 \%$ were either separated or divorced. Majority of the households were female-headed $(54.5 \%)$, while $45.7 \%$ were male-headed. About a quarter, $24.2 \%$, of the elderly were living alone, $22.5 \%$ were living with one other person. The mean household size was 3.26.

About $46.0 \%$ of the respondents were not in any form of employment. The various forms of occupations included $9.7 \%$ in formal employment, farmers $12.5 \%, 12.5 \%$ housewife / farmers, business $11.4 \%$, and $8.0 \%$ in self-employment (Table 1).
The various sources of income and livelihood for the households included business $22.0 \%$, crop farming $17.1 \%$, formal employment $16.8 \%$ while $16.8 \%$ survived on gifts from friends. Other sources were $15.4 \%, 8.7 \%$ and $3.1 \%$ who got their income and livelihood from casual work, crops and livestock farming and livestock farming respectively.

\section{Oral health status}

Condition of oral mucosa: Most of the respondents $(88.9 \%)$ had no visible oral mucosal lesions, 3.6\% had an abscess, 2.0\% had leucoplakia, 2.0\% had smoker's palate, $1.6 \%$ apthous ulceration, and $0.8 \%$ had oral candidiasis.

Periodontal status and wasting diseases of teeth: The most common factors associated with periodontal diseases observed included plaque $89.9 \%$, calculus $85.6 \%$, gum recession $82.5 \%$, tooth mobility $51.2 \%$ and bleeding gums in $77.4 \%$. Among the wasting diseases of the teeth, attrition was the most common in $59.6 \%$ of the respondents, followed by abrasion $13.6 \%$, while erosion was observed in only $0.9 \%$ (Table 2 ).

Prosthetic status: About 1.3\% of the respondents were completely edentulous, and majority of them had no dental prostheses, although they had missing teeth. Table 3 shows the respondents by type of prostheses.

Table 1

Main source of income/livelihood for respondents $(n=289)$

\begin{tabular}{lrrrrrr}
\hline \multirow{2}{*}{ Source of income/livelihood } & \multicolumn{2}{c}{ Females } & \multicolumn{2}{c}{ Males } & \multicolumn{2}{c}{ Total } \\
& No. & $(\%)$ & No. & $(\%)$ & No. & $(\%)$ \\
\hline Employment & 26 & 54.2 & 22 & 45.8 & 48 & 16.8 \\
Crops farming & 31 & 63.3 & 18 & 36.7 & 49 & 17.1 \\
Livestock farming & 3 & 33.3 & 6 & 66.7 & 9 & 3.1 \\
Crops and livestock farming & 16 & 64.0 & 9 & 36.0 & 25 & 8.7 \\
Business & 41 & 65.1 & 22 & 34.9 & 63 & 22.0 \\
Gifts from friends and relatives & 40 & 83.3 & 8 & 16.7 & 48 & 16.8 \\
Casual work & 32 & 72.7 & 12 & 27.3 & 44 & 15.4 \\
\hline Total & 189 & & 97 & & 286 & 100 \\
\hline
\end{tabular}


Table 2

Distribution of dental conditions encountered in 289 elderly persons

\begin{tabular}{lrrrrrr}
\hline Condition & \multicolumn{2}{c}{ Males } & \multicolumn{2}{c}{ Females } & \multicolumn{2}{c}{ Total } \\
& No. & $(\%)$ & No. & $(\%)$ & No. & $(\%)$ \\
\hline Calculus & 82 & 34.6 & 155 & 65.4 & 237 & 85.6 \\
Plaque & 87 & 34.9 & 162 & 65.1 & 245 & 89.9 \\
Bleeding gums & 78 & 36.8 & 134 & 63.2 & 212 & 77.4 \\
Gum recession & 79 & 34.8 & 148 & 65.2 & 227 & 82.5 \\
Tooth mobility & 43 & 25.7 & 124 & 74.3 & 167 & 51.2 \\
Attrition & 50 & 32.3 & 105 & 67.7 & 155 & 59.6 \\
Abrasion & 6 & 19.4 & 25 & 80.6 & 31 & 13.6 \\
Erosion & 1 & 50.0 & 1 & 50.0 & 2 & 0.9 \\
\hline
\end{tabular}

Table 3

Respondents by type and number of prostheses

\begin{tabular}{lcccc}
\hline \multirow{2}{*}{ Type of prostheses } & \multicolumn{2}{c}{ Upper jaw } & \multicolumn{2}{c}{ Lower jaw } \\
& No. & $(\%)$ & No. & $(\%)$ \\
\hline None & 263 & 95.6 & 265 & 96.4 \\
One bridge & 1 & 0.4 & 0 & 0 \\
More than one bridge & 1 & 0.4 & 0 & 0 \\
Partial removable denture & 3 & 1.1 & 3 & 1.1 \\
Full removable denture & 7 & 2.5 & 7 & 2.5 \\
\hline
\end{tabular}

Dental caries experience: The proportion of respondents who were caries free was $19.7 \%$. The missing teeth component accounted for $56.3 \%$ of the total decayed missing and filled teeth (DMFT), while the filled and decayed components accounted for 1.9 and $41.8 \%$ respectively. The teeth that were least affected included the maxillary and mandibular incisors compared to the rest of the teeth (Table 4a). The mean DMFT for the sample was 7.173 , with the females being more affected than the male with a DMFT of 7.70 and 5.96 respectively (Table $4 b$ ).

The respondents were examined for root caries. Majority of them $(79.6 \%)$, had no decayed or filled roots, $6.9 \%$ had at least one decayed or filled root while $2.8 \%$ had two roots affected and $2.8 \%$ had three affected roots. The mean root caries experience was 0.817 .

\section{Nutritional status}

The mean BMI was 24.9 and the level of global malnutrition was $11.4 \%$ using a BMI cut off of $<18.5$.
Overweight was present in $40.9 \%$ of respondents, with more females than males being overweight. The mean MUAC for the group was 29.2 and the cut off points used were $<22 \mathrm{~cm}$ for women and $<23$ $\mathrm{cm}$ for men. The anthropometric cut offs used were according to WHO recommendations (9). Table 5 shows the mean anthropometric measurements and the nutritional status of the respondents by gender, while Table 6 shows the BMI by age groups.

Nutritional status and risk factors: A total of $69.1 \%$ respondents controlled the household income. The respondents who controlled the household income had the highest percentage $(81.1 \%)$ of normal nutrition status. Where the income was controlled by another person, the respondents were more likely to be malnourished, overweight or obese. This relationship was found to be of statistical significance, $(X=18.952, P=0.000)$. The other factors with a significant relationship with nutrition status were age and sex $(\mathrm{p}<0.05)$. Table 5 and 6 shows the BMI by sex and age. 


\section{Table 4a}

Decayed missing and filled teeth by type $(n=2073)$

\begin{tabular}{lccc}
\hline Teeth & No. decayed & No. missing & No. filled \\
\hline Mandibular molars & 308 & 345 & 5 \\
Maxillary molars & 292 & 290 & 13 \\
Mandibular premolars & 85 & 116 & 2 \\
Maxillary premolars & 86 & 115 & 13 \\
Mandibular canines & 14 & 45 & 0 \\
Maxillary canines & 23 & 40 & 1 \\
Maxillary incisors & 40 & 101 & 5 \\
Mandibular incisors & 18 & 116 & 0 \\
\hline Total & 866 & 1168 & 39 \\
\hline
\end{tabular}

\section{Table $4 \mathrm{~b}$}

Decayed missing and filled teeth index

\begin{tabular}{lcccc}
\hline Component & No. of teeth & Dotal & Male & Female \\
\hline Decayed & & $(\mathrm{Dt}) 2.997$ & 2.84 & 3.06 \\
Missing & 866 & $(\mathrm{Mt}) 4.041$ & 3.0 & 4.50 \\
Filled & 1168 & $(\mathrm{Ft}) 0.135$ & 0.12 & 0.14 \\
\hline Total & 39 & $(\mathrm{DMFT}) 7.173$ & 5.96 & 7.70 \\
\hline
\end{tabular}

Table 5

Mean anthropometric measurements and nutritional status ( $n=289$ )

\begin{tabular}{lcccccccccc}
\hline & $\begin{array}{l}\text { Weight } \\
(\mathrm{Kg})\end{array}$ & $\begin{array}{c}\text { Height } \\
(\mathrm{cm})\end{array}$ & BMI & MUAC & \multicolumn{3}{c}{ BMI categories (\% of respondents) } & \multicolumn{2}{c}{ MUAC categories } \\
& & & & & $<16$ & $\begin{array}{c}16 \text { to } \\
\text { 18.5 to }\end{array}$ & 25 to & $30+$ & (\% respondents $)$ \\
\hline All & 63 & 159.2 & 24.9 & 29.2 & 3.5 & 8.1 & 47 & 24.9 & 16.5 & 18.8 \\
Male & 62 & 165 & 22.8 & 27.7 & 4.7 & 10.6 & 58.8 & 20.0 & 5.9 & 9.4 \\
Female & 63.4 & 156.4 & 25.7 & 29.8 & 3.0 & 7.0 & 42.0 & 27.0 & 21.0 & 7.4 \\
\hline
\end{tabular}

Table 6

Body mass index by age groups $(n=285)$

\begin{tabular}{lcccc}
\hline BMI Category & $\begin{array}{c}45-54 \text { years }(\mathrm{n}=110) \\
\% \text { of respondents }\end{array}$ & $\begin{array}{c}\text { 55-64 years }(\mathrm{n}=74) \\
\text { \% of respondents }\end{array}$ & $\begin{array}{c}\text { 65+ years }(\mathrm{n}=101) \\
\text { \% of respondents }\end{array}$ & Total \\
\hline$<16$ & 10 & 10 & 80 & 10 \\
$16-18.49$ & 30.4 & 30.4 & 39.2 & 23 \\
$18.5-24.99$ & 36.1 & 27.8 & 36.1 & 133 \\
$25-29.99$ & 50.7 & 19.7 & 29.6 & 71 \\
$\geq 30$ & 37.5 & 31.3 & 31.3 & 48 \\
\hline
\end{tabular}


Table 7

Factors found to be statistically significant in relation to BMI score

\begin{tabular}{lcc}
\hline Variable & $\mathrm{X}^{2}$ & P-value \\
\hline Age & 9.011 & 0.0138 \\
Sex & 12.082 & 0.00258 \\
Tooth mobility & 13.859 & 0.00098 \\
Caries experience & 7.025 & 0.0281 \\
Poor strength & 15.734 & 0.00038 \\
Poor manual dexterity & 22.188 & 0.00002 \\
Physical disability & 23.107 & 0.00001 \\
Low budget for food & 7.150 & 0.02802 \\
\hline
\end{tabular}

Nutritional status and oral health: Over half of the respondents, $60.7 \%$, had visited a dentist in their lifetime. Among 134 respondents with normal BMI, $56.7 \%$ reported having visited a dentist. Majority of the respondents who were malnourished had never visited a dentist, 57.6\%. The difference between BMI score for those who had paid a visit to the dentist and those who had not was statistically significant $\left(X^{2}=10.108, p=0.018\right)$. There was an inverse relationship between nutritional status (BMI) and tooth mobility.

\section{DISCUSSION}

The aim of this study was to determine the nutritional and oral health status of elderly persons in Dagoretti Division of Nairobi province, with a goal to provide an overview on the nutrition and oral health status of an elderly population in a peri-urban Division in Nairobi. Both qualitative and quantitative methods were used to collect data. A total of 289 respondents were interviewed in the households, with an age range of $45-115$ years.

Socio-demographic characteristics: Illiteracy levels were high with $43 \%$ of the respondents having never been to school, and only $8.3 \%$ had completed primary education. The mean household size was 3.3 and $24 \%$ of the elderly were living alone.

The major problem faced by the elderly was limited access to finances as reported by $58.5 \%$ of the respondents. This is in line with past studies which have shown that people in developing countries enter old age of deprivation due to lack of established social care, and this is made worse by the added burden of having to take care of grand children who have been orphaned or abandoned (10).
There are no formal supporting structures for old persons, and thus they felt neglected and left out by the society.

Oral health status: The study provides information on the oral health status of peri-urban low to middle class elderly persons living on the outskirts of Nairobi City. Majority had plaque and calculus despite $85.1 \%$ reporting regular brushing of teeth. Gingivitis was also prevalent with $77.4 \%$ exhibiting bleeding on probing. Studies involving young adults in Kenya have also reported presence of abundant plaque and calculus despite claims of daily brushing of teeth $(11,12)$. This probably implies that the effectiveness of brushing is not adequate and calls for education on proper brushing techniques (13).

Periodontal tissue breakdown was evident as demonstrated by gingival recession in $82.5 \%$ of the individuals and mobility of teeth reported in $51.9 \%$. These figures are similar to findings reported in middle aged rural Tanzanians (14). Abundant plaque, calculus and recession appear to be a common finding in this population in Tanzania also $(15,16)$. A big proportion of respondents $(59 \%)$ had attrition.

The level of edentulousness was $2.5 \%$ and this explains the low level of dental prosthesis in this population. The mean number of mobile teeth was 3.291 ( $n=2073)$ with the highest number of mobile teeth in one individual being 22 . There was an inverse relationship between nutritional status and tooth mobility probably implying that compromised mastication may have contributed to this relationship. The DMFT was high due to the missing teeth component. It appears extraction may have been the treatment of choice in these individuals probably due to the unavailability of dental services and prohibitive cost of treatment (13). 
Nutritional status: The level of under nutrition using the MUAC was $18.8 \%$ while by BMI it was $11.4 \%$. There were more males than females classified as malnourished. The level of overweight was high at $40.9 \%$ with more females than males being overweight. These results compare well with past studies which have shown that obesity is more common among elderly women than men (17). However, the problem of overweight was more common in the age groups 45 to 54 years, while underweight was more common in the age group 65 years and above. Both under nutrition and obesity were problems faced by the elderly in this study. These findings compare with similar studies done in Kenya and other countries, in which the prevalence of malnutrition among free living elderly ranges between 5 to $10 \%$ (17). During times of food scarcity, social pressures discriminate against the elderly in intra-household food distribution. The selective food habits of the elderly dictated by financial status, physical and functional ability, dental health, physiological and psychological status could also contribute to malnutrition (18). On the other hand, some of the old people tend to consume more of carbohydrate foods and they were not engaged in vigorous physical activities and this could have contributed to overweight. Physical, social and emotional problems reported by the elderly could interfere with appetite, affect the ability to purchase, prepare and consume an adequate diet (19).

Majority of the respondents $(57.6 \%)$ who were malnourished had never visited a dentist. This could imply that their dental health may have interfered with their food intake, and thus compromised their nutritional status. Other factors contributing significantly to the nutritional status included income control, gender, tooth mobility, caries experience and the following risk factors: poor manual dexterity, physical disability, alcoholism, tobacco use, low budget for food, recent injury, and poor eyesight (Table 7). Studies have shown that old age for most Africans is normally associated with poor access to health care and a diet that is usually inadequate in quantity and quality (20). Nutrition interventions in Africa have however focussed on children and pregnant/lactating women leaving out old people who are not considered as a priority group.
In conclusion, the study established that many of the elderly persons suffered from dental problems, especially periodontitis, dental caries, tooth mobility and missing teeth. The level of malnutrition using the MUAC was $18.8 \%$ while by BMI it was $11.4 \%$, $46.4 \%$ had normal nutritional status while $40.9 \%$ were overweight, with more females $(48.0 \%)$ than males $(25.9 \%)$ being overweight. Thus under nutrition, obesity and dental problems are issues of concern among this elderly population.

We recommend that, there is need to develop policies that will look into the nutritional and dental health of the elderly in order to improve their welfare. There is also need for advocacy on the rights of the elderly as well as creation of awareness on the problems they face.

\section{ACKNOWLEDGEMENTS}

To HelpAge International for funding this study, HelpAge Kenya for providing logistics and participating in the research, Colgate-Palmolive Kenya for assisting with transport and the dental students who assisted with data collection.

\section{REFERENCES}

1. UN. The United States. Bureau of the census, 1996.

2. UN. Fourth Report on the World Nutrition Situation 2000; p 19.

3. CBS. The Kenya Demographic and Health Survey 2003; 215-216.

4. Cawson, R.A. Dental caries. In. Essentials of dental surgery and pathology. $7^{\text {th }}$ Edition. Churchill Livingston. 2002; 31-70.

5. UNICEF/GOK. Situation analysis of women and children in Kenya. 1998; 214-216.

6. WHO. Global goals for oral health in the year 2000; FDI. Int. Dent. J. 1982; 32: 74-77.

7. Ulla, K. and Peterson, P.E. Periodontal conditions in 35-44 and 65-74 year old adults in Demark. Acta. Odontologica Scadinavica. 2006; 64: 65-73.

8. WHO Oral Health Surveys: Basic Methods, Geneva: $4^{\text {th }}$ Edition 1997.

9. WHO. Adults 60 years of age and older. In: Physical status: The use and interpretation of anthropometry. 
Report of a WHO Expert Committee, Technical Report Series No. 854, Ch. 9, Geneva: WHO. 1995.

10. UN-Fourth report on the World Nutrition situation. 2000; 19.

11. Wagaiyu, E.G., Wagaiyu, C.K., Valderhaug, J. and Arneberg, P. A survey of periodontal health in Kenyan National Youth Trainees. Scand. Assoc. Den.Res. IADR. 1988; Abstr. 73.

12. Chindia, M.L., Valderhaug, J. and Ng'ang'a P.M. Oral health habits and periodontal health among a group of University students in Kenya. East Afr. Med. J. 1992; 69: 337-340.

13. Petersen, E.P. and Tatsuo, Y. Improving the oral health of older people: the approach of WHO global oral health programme. Comm. Dent. Oral Epidemiol. 2005; 33: 81-92.

14. Mumghamba, E.G.S. and Fabian, F.M. Peridontal health status and oral hygiene practices among middle aged adults in Mtwara, rural Tanzania. Afr. J. Oral Health Sci. 2003; 4: 192-197.
15. Baelum, V. Pattern of periodontal breakdown in adult Tanzanians. Scand. J. Dent. Res. 1987; 95: 221-228.

16. Lembariti, B.S., Frencken, J.F. and Pilot, T. Prevalence and severity of periodontal conditions among adults in urban and rural Morogoro, Tanzania. Comm. Dent. Oral Epidemiol. 1988; 16: 240-243.

17 Cederholm, C. and Hellerstrom, K. Nutritional status in recently hospitalized and free-living elderly subjects. Gerontology. 1992; 38: 105-110.

18. Horwath, C.C. Nutrition goals for elderly adults: A review. Gerontol. 1991; 31: 811-821.

19. Russell, R.M, Sahyoun, N.R. In: The elderly in clinical nutrition, $2^{\text {nd }}$ Edition. Washington D.C., C.V. Mosby, $1988 ; 110$.

20. Charlton, K.E. and Rose, D. Nutrition among older adults in Africa: the situation at the beginning of the millennium. J. Nutr. 2001; 131: 2424S-2428S. 